Supporting Information

\title{
Effect of Monovalent Metal Iodide Additive on Optoelectric Properties of Two-Dimensional Sn-based Perovskite Films
}

Youjin Reo ${ }^{1 \dagger}$, Huihui Zhu ${ }^{1 \dagger}$, Ji-Young Go ${ }^{1 \dagger}$, Kyu In Shim ${ }^{2}$, Ao Liu ${ }^{1}$, Taoyu Zou ${ }^{1}$, Haksoon Jung ${ }^{1}$, Hyunjun $\mathrm{Kim}^{1}$, Jisu Hong ${ }^{1}$, Jeong Woo Han ${ }^{2 *}$, Yong-Young Noh ${ }^{1 *}$

${ }^{1}$ Department of Chemical Engineering, Pohang University of Science and Technology (POSTECH), Pohang, Gyeongbuk, 37673, Republic of Korea

${ }^{2}$ Department of Chemical Engineering and School of Interdisciplinary Bioscience and Bioengineering, Pohang University of Science and Technology (POSTECH), Pohang, Gyeongbuk, 37673, Republic of Korea

$\dagger$ These authors contributed equally.

*Corresponding authors

E-mail: yynoh@postech.ac.kr, Tel: +82-54-279-226

E-mail: jwhan@postech.ac.kr, Tel: +82-54-279-2265

\section{Tables S1}

Figures S1-S9 
Table S1. Formation energies and relative formation energies of pristine and $\mathrm{Cu}^{+}, \mathrm{Na}^{+}$and $\mathrm{Ag}^{+}-\mathrm{doped}$ $(\mathrm{PEA})_{2} \mathrm{SnI}_{4}$.

\begin{tabular}{ccc}
\hline Dopant & $\begin{array}{c}\mathbf{E}_{\text {Formation }} \\
(\mathbf{e V})\end{array}$ & $\begin{array}{c}\mathbf{E}_{\text {Relative formation }} \\
(\mathbf{e V})\end{array}$ \\
\hline $\mathrm{Sn}^{2+}($ Pristine $)$ & -39.60 & 0.00 \\
$\mathrm{Cu}^{+}$ & -39.08 & 0.52 \\
$\mathrm{Na}^{+}$ & -38.55 & 1.04 \\
$\mathrm{Ag}^{+}$ & -38.10 & 1.49 \\
\hline
\end{tabular}




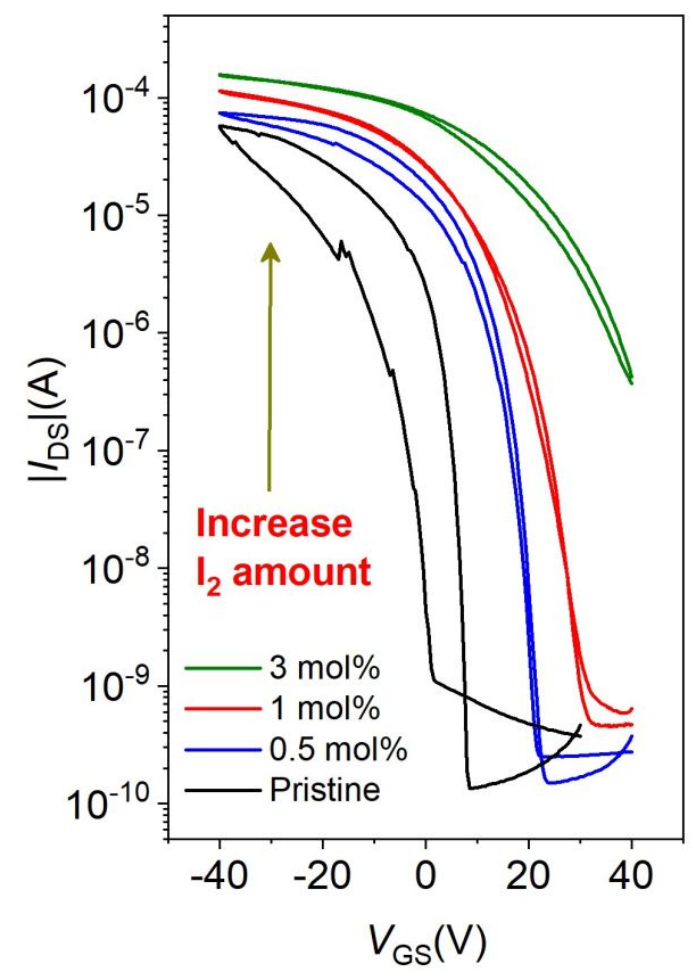

Figure S1. Transfer curves of (PEA $)_{2} \mathrm{SnI}_{4}$ TFTs with different amount of $\mathrm{I}_{2}$ addition. 

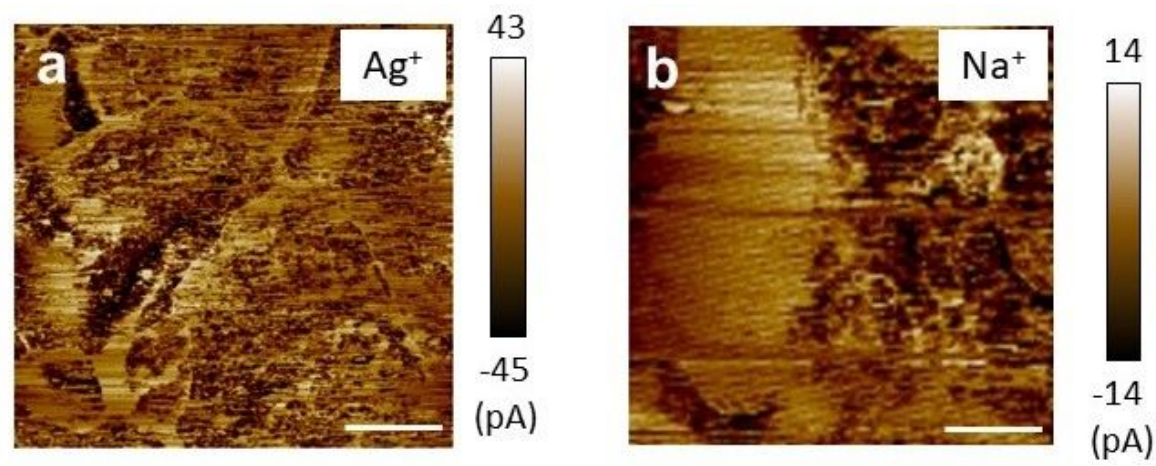

Figure S2. Conductive atomic force microscope (C-AFM) images of (a) $10 \% \mathrm{AgI}(\mathrm{PEA})_{2} \mathrm{SnI}_{4}$ and (b) $10 \% \mathrm{NaI}-(\mathrm{PEA})_{2} \mathrm{SnI}_{4}$ perovskite thin films (scale bar: $0.5 \mu \mathrm{m}$ ). 


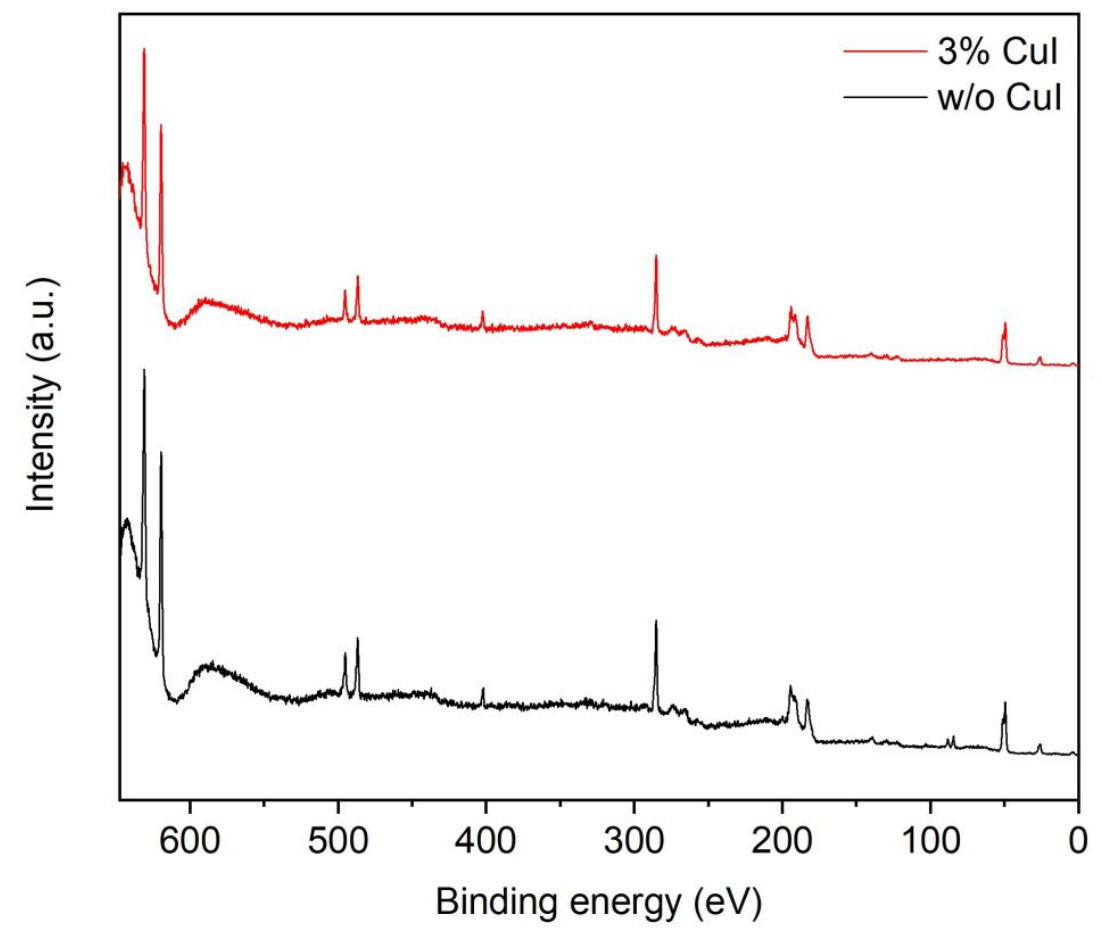

Figure S3. X-ray photoelectron spectroscopy (XPS) wide spectra for (PEA)2SnI4 and $3 \mathrm{~mol} \% \mathrm{CuI}-$ added perovskite thin films. 


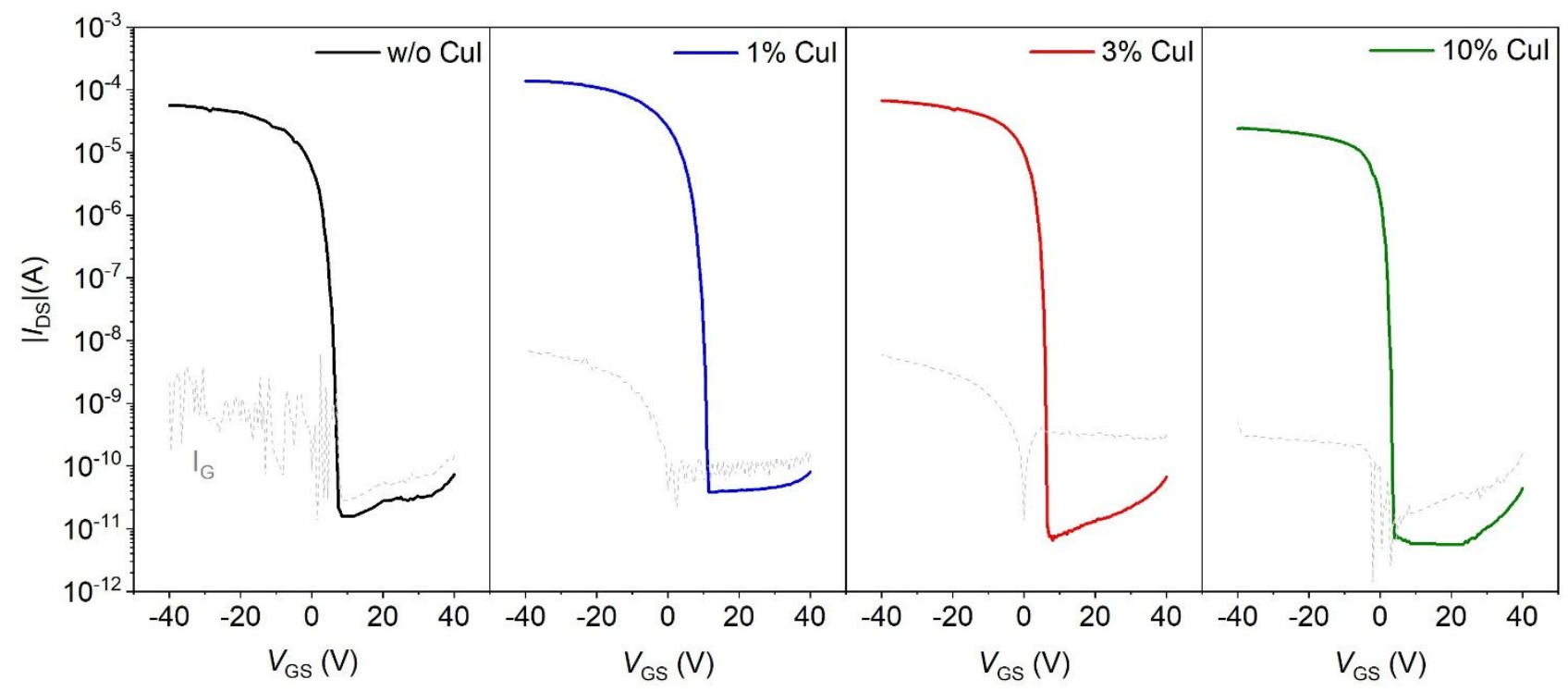

Figure S4. Transfer characteristics of pristine, 1, 3 and $10 \mathrm{~mol} \% \mathrm{CuI}$-incorporated (PEA) $)_{2} \mathrm{SnI}_{4} \mathrm{TFTs}$ using DMSO/DMF solvent engineering $\left(\mathrm{PEAI} \cdot \mathrm{SnI}_{2} \cdot \mathrm{DMSO}_{0.5} \mathrm{DMF}_{0.5}\right)$. 

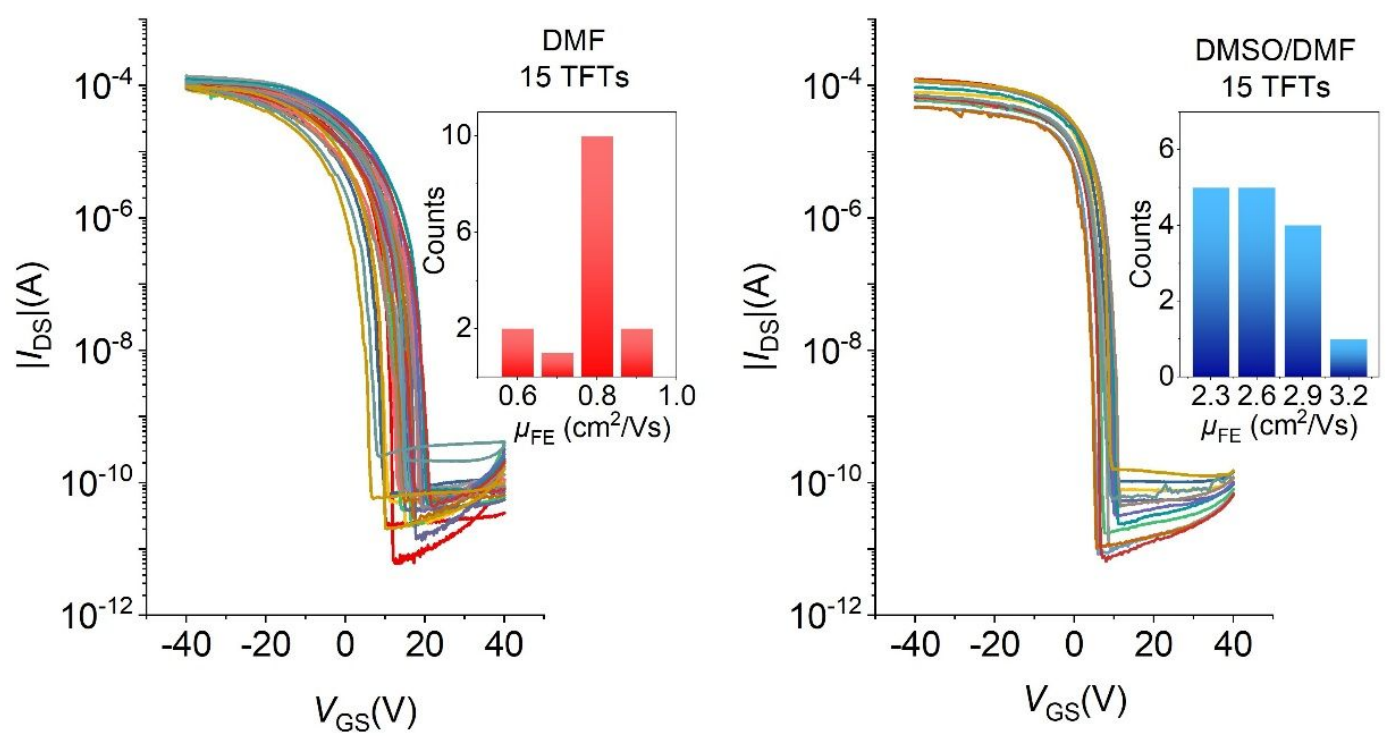

Figure S5. Transfer characteristics and $\mu_{\mathrm{FE}}$ statistics of 15 individual $3 \mathrm{~mol} \% \mathrm{CuI}(\mathrm{PEA})_{2} \mathrm{SnI}_{4} \mathrm{TFTs}$ with (a) DMF and (b) DMSO/DMF solvent 


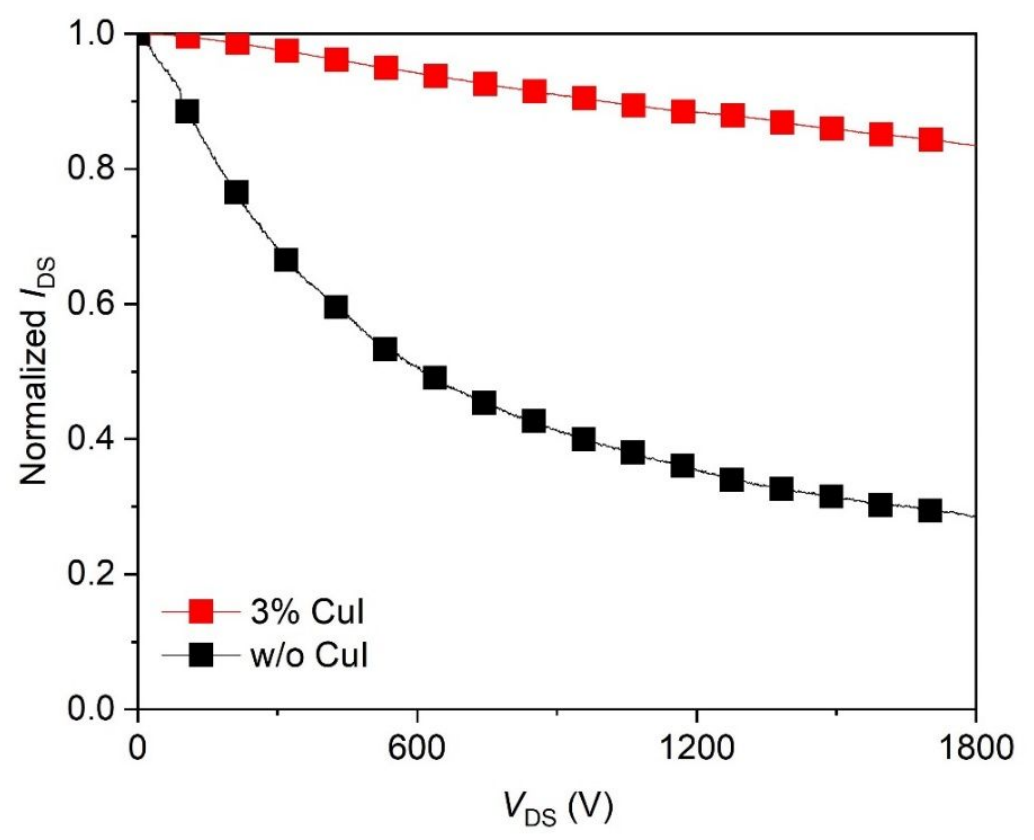

Figure S6. Bias stress test results of pristine and $3 \mathrm{~mol} \% \mathrm{CuI}$-incorporated $(\mathrm{PEA})_{2} \mathrm{SnI}_{4} \mathrm{TFTs}_{\text {. }}$ Normalized drain current $I_{\mathrm{DS}}(\mathrm{t}) / I_{\mathrm{DS}}(0)\left(\mathrm{t}\right.$ is time and $I_{\mathrm{DS}}(0)$ is pristine drain current) under constant bias stress $\left(V_{\mathrm{GS}}=-40 \mathrm{~V}, V_{\mathrm{DS}}=-40 \mathrm{~V}\right.$ for $\left.1800 \mathrm{~s}\right)$. 


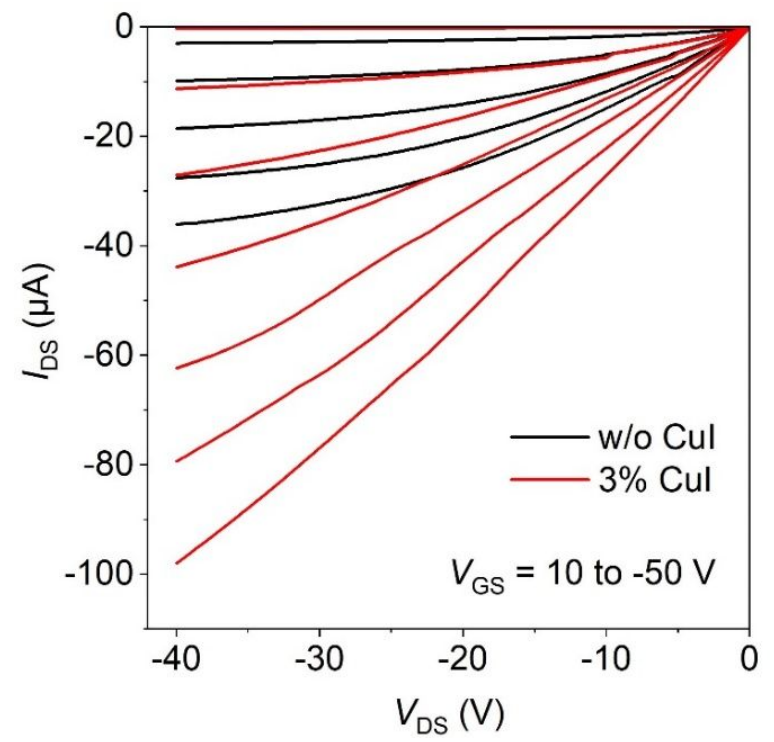

Figure S7. Output curves of pristine and $3 \mathrm{~mol} \% \mathrm{CuI}$-incorporated (PEA) $)_{2} \mathrm{SnI}_{4}$ TFTs. 

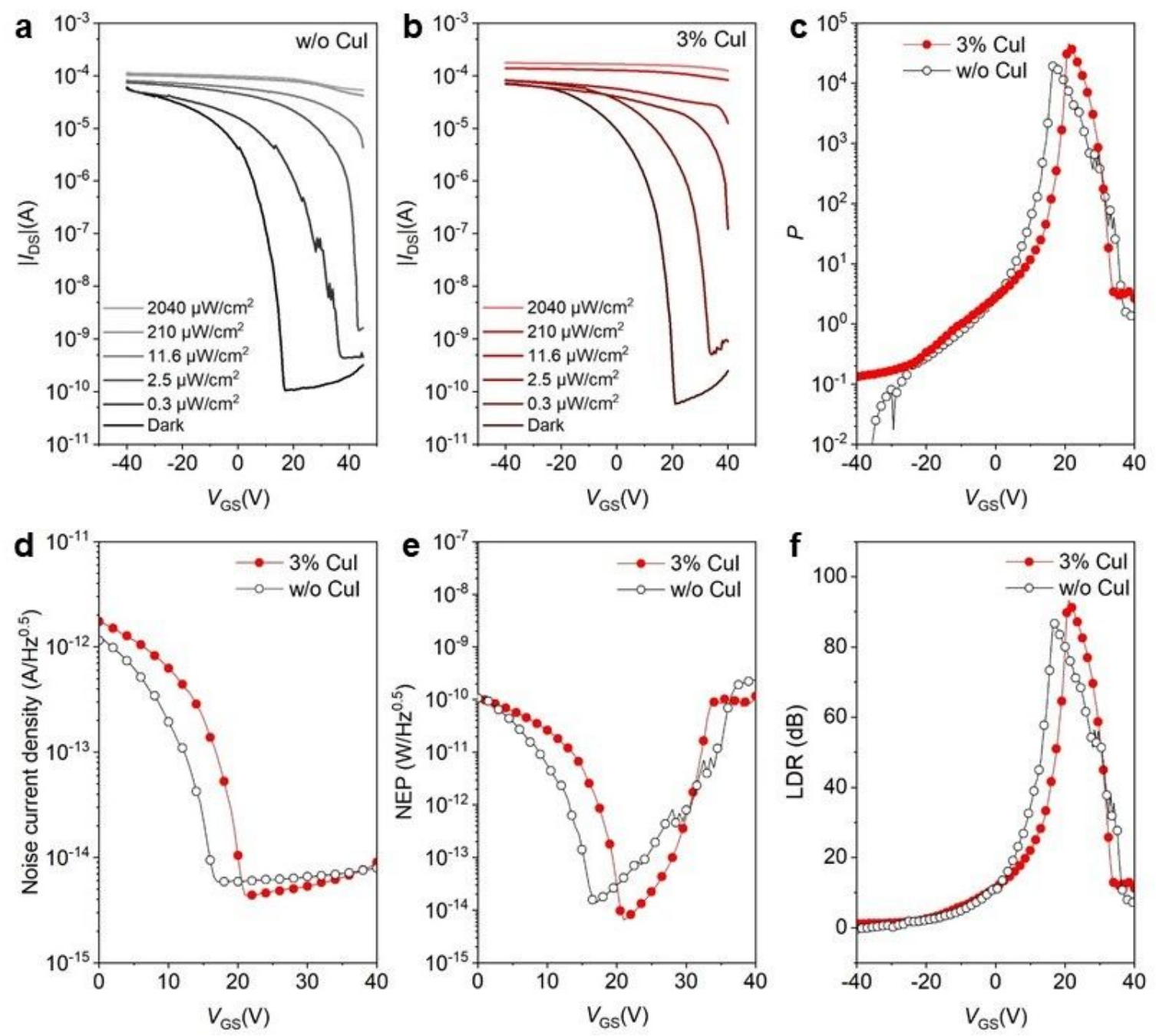

Figure S8. Transfer characteristics of (a) pristine and (b) $3 \mathrm{~mol} \% \mathrm{CuI}$-involved (PEA) ${ }_{2} \mathrm{SnI}_{4}$ phototransistors under dark and various light conditions. (c-f) Phototransistor performance parameters, including photosensitivity $(\mathrm{P})$, noise current density, NEP and LDR.

LDR values are 87 and $93 \mathrm{~dB}$ for pristine and CuI-added phototransistors, which are higher than that of InGaAs photodetectors $(66 \mathrm{~dB})$ and close to that of Si photodetectors $(120 \mathrm{~dB})$. In addition, both pristine and $\mathrm{CuI}$-involved phototransistors exhibited extremely low noise current density of $\sim 10^{-}$ ${ }^{15} \mathrm{~A} / \mathrm{Hz}^{0.5}$. NEP signifies the minimum optical power that a photodetector is able to detect, which decreased from pristine of $5.84 \times 10^{-15}$ to $4.36 \times 10^{-15}$. 


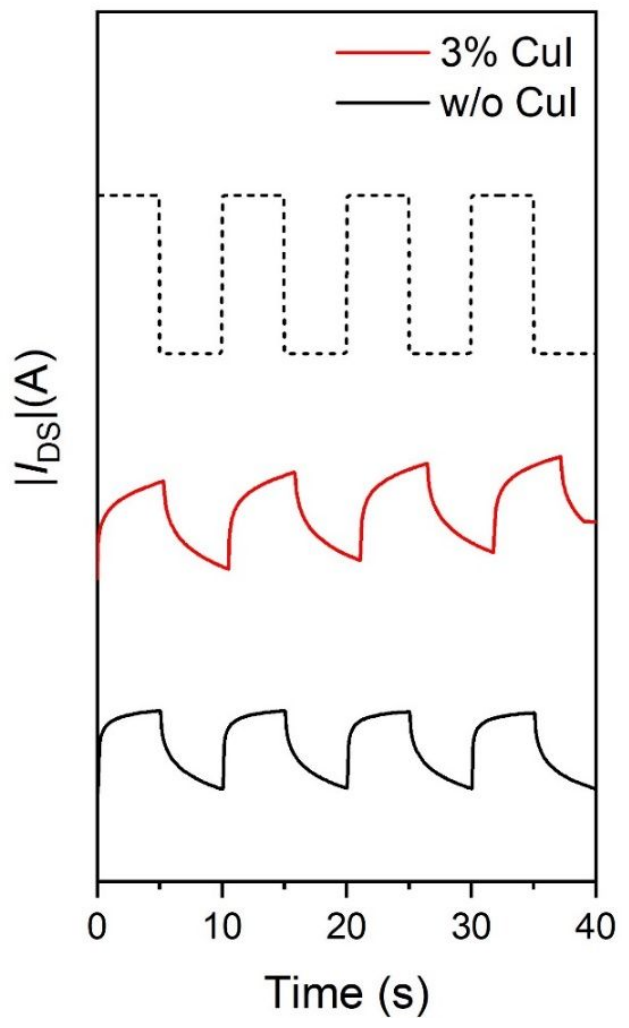

Figure S9. On-off photo modulation of (PEA $)_{2} \mathrm{SnI}_{4}$ and $\mathrm{CuI}-(\mathrm{PEA})_{2} \mathrm{SnI}_{4}$ phototransistors. 